\title{
Assessment of genetic diversity of Tea (Camellia sinensis L.O. Kuntze) as revealed by RAPD - PCR markers
}

\author{
W.A.S.N.S.T. Goonetilleke ${ }^{1 *}$, P.G.C. Priyantha ${ }^{1}$, K.M. Mewan ${ }^{1}$ and M.T.K. Gunasekare ${ }^{2}$ \\ ${ }^{\prime}$ Biochemistry Division, The Tea Research Institute of Sri Lanka, St. Coombs Estate, Talawakelle. \\ ${ }^{2}$ Plant Breeding Division, The Tea Research Institute of Sri Lanka, St. Coombs Estate, Talawakelle.
}

Tea (Camellia sinensis) is one of the principal export plantation crops in Sri Lanka. It has contributed 1.2\% of GDP to the economy of the country in the year $2005^{1}$. There are 64 tea cultivars recommended for commercial planting in Sri Lanka. However, most of the tea plantations contain only a few selected cultivars developed by Tea Research Insitute (TRI), such as TRI 2025. This drastically narrows the genetic diversity in commercial plantations and the breeding population. Therefore conservation of tea genetic resources and broadening the genetic base of the crop are pre-requisites for an effective crop management programme to ensure the sustainability of tea industry. The systematic assessment of genetic variability present in the germplasm collection provides an approach to identify parents based on true genetic differences. This is important in selecting parents for generating heterosis by hybridization.

At present, characterisation of tea cultivars in Sri Lanka is done by morphological assessment of leaf and floral characteristics ${ }^{2,3}$ and by molecular characterisation, such as Random Amplified Polymorphic DNA (RAPD) ${ }^{4}$. It is essential to characterise the whole germplasm collection for rational selection of progenitors for breeding programmes and also to allocate priorities for their conservation. Therefore, the current study was aimed at assessing the genetic diversity of forty six (46) tea cultivars as an extension to a previous study conducted to develop a molecular based criterion for characterisation of tea germplasm.

Forty-six tea cultivars, representing 32 TRI cultivars and 14 estate selections maintained in the ex-situ field gene banks at the TRI, Talawakelle and Ratnapura were selected for this study (Table 1).
Genomic DNA was extracted from the flush (bud and the two tender leaves) by the CTAB method of Dassanayake et al. ${ }^{5}$. DNA quantification was done by electrophoresis on $1 \%(\mathrm{w} / \mathrm{v})$ agarose gel using the known concentrations of lambda $(\lambda)$ DNA.

Hundred different operon primers were screened for polymorphism in the initial study to characterise tea germplasm in Sri Lanka and only 20 were found to be polymorphic ${ }^{4}$. Therefore, those 20 polymorphic primers were used in the present study. The PCR amplification was carried out on a thermocycler (Mycycler, Biorad, USA) according to William et al. ${ }^{6}$ The PCR products were separated by electrophoresis on $1.5 \%(\mathrm{w} / \mathrm{v})$ agarose gel in 1xTAE buffer containing $0.5 \mu \mathrm{g} / \mathrm{mL}$ Ethidium Bromide. Fragment size was estimated using 1 kb ladder and the tea cultivar TC9 was used as a standard in each run to minimize run to run or gel to gel variation.

Scoring of bands was on the basis of presence $(=1)$ or absence $(=0)$ of a particular band and all the bands which unambiguously and consistently appeared were used for the analysis. The binary data were used to compute a pair-wise similarity matrix using the Nei \& Li similarity index ${ }^{7}$. Genetic distances (dissimilarity index) between the cultivars were calculated and cluster analysis was done using the UPGMA (Unweighted PairGroup Method with Arithmetic Average).

RAPD analysis with 20 primers produced 243 scorable bands, out of which 242 (99.6\%) were polymorphic. The number of amplified products by each primer varied from 8 to 18 . Average number of bands per primer was 12 . The molecular weights of bands analysed ranged between $175-3750 \mathrm{bp}$. 
Table 1: The 46 tea accessions and their origin

\begin{tabular}{|c|c|}
\hline Accession & Pedigree \\
\hline TRI 2020 & ASM 4/10 O.P. \\
\hline TRI 2024 & ASM 4/10 O.P. \\
\hline TRI 3014 & TRI 2025 O.P. \\
\hline TRI 3015 & TRI 2026 O.P. \\
\hline TRI 3017 & ASM 4/10 X DT 95 \\
\hline TRI 3021 & TRI 2024 O.P. \\
\hline TRI 3035 & TRI 2025 O.P. \\
\hline TRI 3041 & ASM 4/10 O.P. \\
\hline TRI 3047 & ASM 4/10 O.P. \\
\hline TRI 3058 & ASM 4/10 O.P. \\
\hline TRI 3073 & TRI 2025 O.P. \\
\hline TRI 4001 & ASM 4/10 X TRI 777 \\
\hline TRI 4002 & ASM 4/10 X TRI 777 \\
\hline TRI 4004 & TRI 777 X TRI 2026 \\
\hline TRI 4014 & TRI 2026 X TRI 2023 \\
\hline TRI 4024 & TRI 2023 X TRI 2026 \\
\hline TRI 4027 & TRI 2026 X TRI 777 \\
\hline TRI 4028 & ASM 4/10 X TRI 777 \\
\hline TRI 4030 & TRI 777 X TRI 2026 \\
\hline TRI 4034 & TRI 2026 X TRI 2023 \\
\hline TRI 4043 & TRI 2026 X TRI 2023 \\
\hline TRI 4047 & CY 9 X ASM 4/10 \\
\hline TRI 4049 & CY 9 X ASM 4/10 \\
\hline TRI 4053 & CY 9 X ASM 4/10 \\
\hline TRI 4059 & TRI 2020 X TRI 2023 \\
\hline TRI 4063 & TRI 2020 X TRI 2025 \\
\hline TRI 4067 & CY 9 X NAY 3 \\
\hline TRI 4076 & N 2 X DN \\
\hline TRI 4085 & TRI 2024 X DN \\
\hline TRI 62/1 & ASM 4/10 O.P. \\
\hline TRI $62 / 5$ & ASM 4/10 O.P. \\
\hline TRI 62/6 & ASM 4/10 O.P. \\
\hline B 275 & Seedling selection from Ragala \\
\hline $\mathrm{CH} 13$ & Seedling selection from Craighead \\
\hline EN 31 & Seedling selection from Endana \\
\hline H $1 / 58$ & Seedling selection from Hulanduwa \\
\hline $\operatorname{HR} 1 / 3$ & Seedling selection from Horrow \\
\hline KP 204 & Seedling selection from Palmgarden \\
\hline K 145 & Seedling selection from Kirikoswald \\
\hline MTBG & Seedling selection from Balangoda \\
\hline PO 26 & Seedling selection from Poronuwa \\
\hline TC 9 & Seedling selection from Tilicoultry \\
\hline TC 10 & Seedling selection from Tilicoultry \\
\hline TRI 1114 & Seedling selection from St. Coombs \\
\hline TRI 2142 & Seedling selection from St. Coombs \\
\hline W 14 & Seedling selection from Waltrim \\
\hline
\end{tabular}

O.P. - Open Pollinated
The dendrogram resolved the 46 tea accessions into 3 different groups (Figure 1). The first group (Group I) comprised of 25 tea accessions. This group is further divided into 3 subgroups and the first subgroup (subgroup I a) contained 2 accessions of TRI cultivars (TRI 1114 and TRI 2142) and the second subgroup (subgroup 1b) consisted of 12 different cultivars which belonged to estate selections. The third sub group (subgroup I c) comprised crosses in which some of their sources of origin were estate selections.

The second group (Group II) comprised TRI cultivars derived from open pollinated progenies.

The third group (Group III) comprised mainly TRI 62 series (a promising seedling selection made from the ASM 4/10) indicating considerable genetic difference between estate selections and TRI 62 series. TRI 62 series and the open pollinated progenies showed very low genetic difference.

The genetic distance estimated from these DNA markers varied from $0.18-0.73$. The average genetic distance within the estate selections was 0.49 whereas TRI cultivars derived from open pollinated progenies and TRI 62 series cultivars were 0.48 and 0.33 respectively. The pair wise genetic distance and cluster analysis revealed existence of considerable genetic diversity among the selected tea cultivars suggesting that the genetic diversity is more within estate selections. Some crosses such as those between estate selections and TRI cultivars (KP 204 and TRI 4085) and some crosses among TRI cultivars (TRI 4034 and TRI 2020) have the potential of generating considerable genetic variation, and hybrid vigor in the future cultivar development programmes for desirable characters, such as pest and disease resistance.

The lowest genetic distance (0.18) was observed between TRI 62/6 and TRI 62/1, indicating that their origin was from the same stock of ASM 4/10. However, the overall grouping of accessions by the cluster analysis showed a moderate genetic distance (0.45) indicating that the overall genetic variability of the gene pool is limited.

The dendrogram shows that TRI 1114 and TRI 2142 are genetically different from other TRI cultivars that were originated from controlled hybridisation and that they are closely related to the estate selections. The naming of those two cultivars with the acronym "TRI" does not imply that they are the result of controlled hybridisation. According to their origin they were selected from seedling populations on St. Coombs Estate and hence belong to estate selection category. 


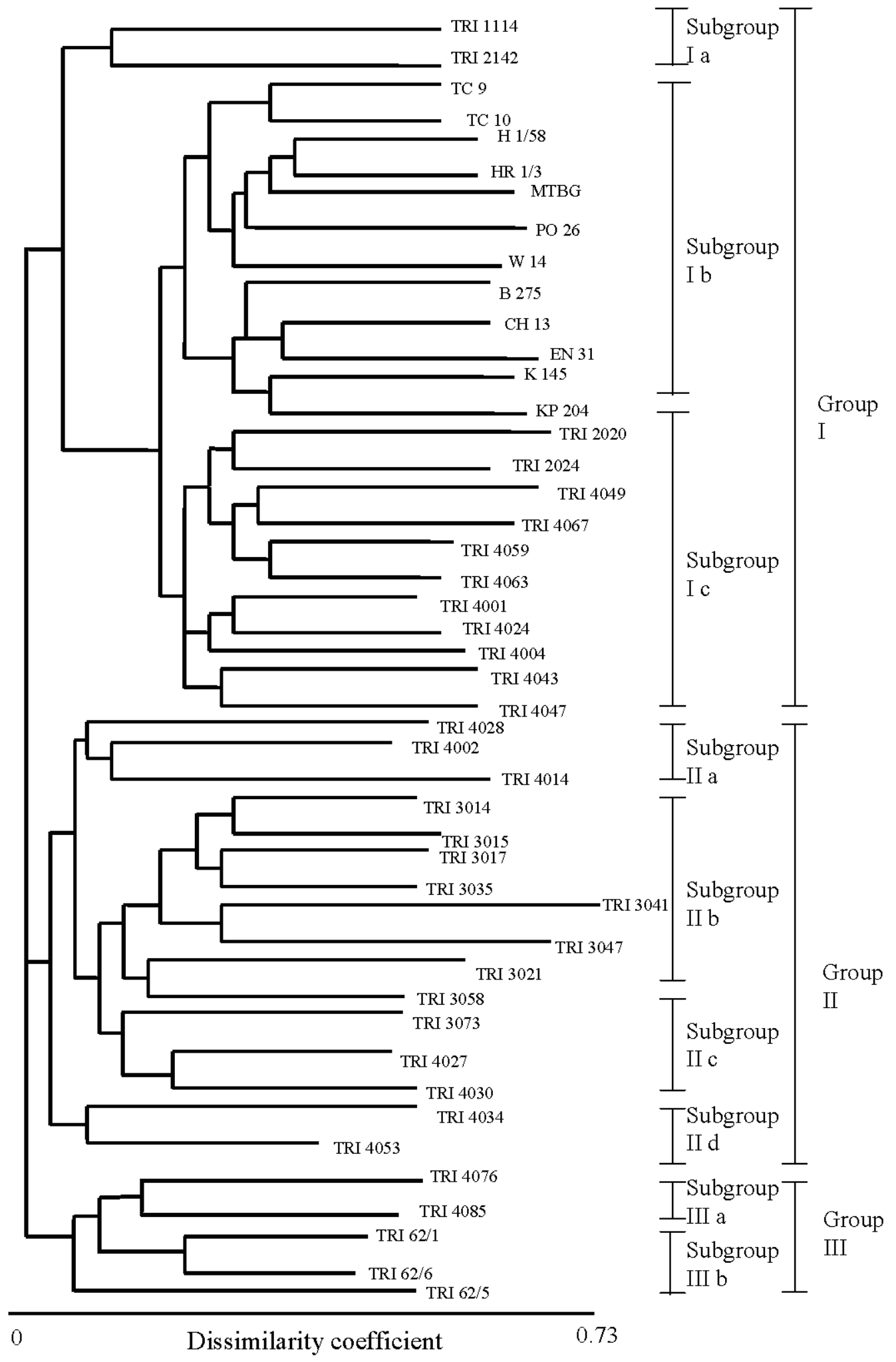

Figure 1: Dendrogram of the 46 tea accessions based on RAPD markers constructed using UPGMA cluster analysis. 
TRI 62 series stood apart from the rest of the group derived from ASM 4/10 open pollinated progenies indicating that they were genetically different from the cultivars derived from ASM 4/10 open pollinated progenies. Morphological details of 62 series showed that they have comparatively larger leaves with high leaf thickness than ASM 4/10.

In conclusion, the information generated from this study showed that there are significant genetic differences among the 46 tea cultivars studied and that they could be used to strengthen the future tea cultivar improvement programme effectively by incorporating potential progenitors from the available tea germpalsm.

\section{References}

1 Central Bank of Sri Lanka (2005). Annual Report. pp. 83. Central Bank, Colombo.

2 Wickramarathne M.R. (1981). Variation in some leaf characteristics in tea (Camellia sinensis) and their use in the identification of tea clones. The Tea Quarterly of Ceylon 50(4): 183-189.
3 Gunasekare M.T.K., Kottawa Arachchige J.D., Mudalige A.K. \& Peiris T.U.S. (2001). Morphological diversity of tea (Camellia sinensis L.) genotypes in Sri Lanka. Proceedings of the $57^{\text {th }}$ Annual Session. p. 83. Sri Lanka Association of Advancement of Science (SLAAS), Colombo.

4 Liyanage A.C., Mewan K.M., Gunasekare M.T.K., Evarad J.M.D. \& Karunanayake K.H. (2001). Use of DNA markers for molecular characterization of Tea (Camellia sinensis L.) clones. Project Report. Council for Agricultural Research Policy (CARP), Colombo.

5 Dassanayake P.N. (1999). RAPD based characterization of coconut cultivars in Sri Lanka. Ph D Thesis. Faculty of Graduate Studies, University of Sri Jayawardanapura, Nugegoda.

6. Williams J.G.K., Kubelik A.R., Livak K., Rafalski J.A. \& Tingy S.V. (1990). DNA Polymorphisms amplified by arbitrary primers are useful as genetic markers. Nucleic Acid Research 18: 6531-6535.

7 Nei M. \& Li W.H. (1979). Mathematical model to study genetic variation in terms of restriction endonucleases. Proceedings of National Academy of Sciences. USA 76(10): 5267-5273. 